\title{
Subcutaneous trastuzumab with pertuzumab and docetaxel in HER2-positive metastatic breast cancer: Final analysis of MetaPHER, a phase IIIb single-arm safety study
}

\author{
Sherko Kuemmel ${ }^{1,2}$ (1) Carlo A. Tondini ${ }^{3}$. Jacinta Abraham ${ }^{4} \cdot$ Zbigniew Nowecki $^{5}$ - Bartosz Itrych ${ }^{6,18}$. Erika Hitre ${ }^{7}$ \\ Bogusława Karaszewska ${ }^{8}$ - Alejandro Juárez-Ramiro ${ }^{9}$. Flavia Morales-Vásquez ${ }^{10}$. Jose Manuel Pérez-García ${ }^{11,19}$. \\ Servando Cardona-Huerta ${ }^{12}$. Estefania Monturus ${ }^{13} \cdot$ Marco Sequi $^{14,15}$ - Eleonora Restuccia ${ }^{13} \cdot$ Mark Benyunes $^{16}$. \\ Miguel Martín ${ }^{17}$
}

Received: 4 January 2021 / Accepted: 8 February 2021 / Published online: 21 March 2021

(c) The Author(s) 2021

\begin{abstract}
Purpose Intravenous trastuzumab, pertuzumab, and docetaxel are first-line standard of care for patients with HER2-positive metastatic breast cancer (mBC). MetaPHER is the first study assessing the safety and tolerability of subcutaneous trastuzumab plus intravenous pertuzumab and chemotherapy in a global patient population with HER2-positive mBC.

Methods In this open-label, single-arm, multicenter, phase 3b study, eligible patients were $\geq 18$ years old with histologically/ cytologically confirmed previously untreated HER2-positive mBC. All received $\geq 1$ subcutaneous trastuzumab 600 mg fixed dose plus intravenous pertuzumab (loading dose: $840 \mathrm{mg} / \mathrm{kg}$; maintenance: $420 \mathrm{mg} / \mathrm{kg}$ ) and docetaxel ( $\geq 6 \mathrm{cycles}$; initial dose $75 \mathrm{mg} / \mathrm{m}^{2}$ ) every 3 weeks. The primary objective was safety and tolerability; secondary objectives included efficacy. Results At clinical cutoff, 276 patients had completed the study; median duration of follow-up was 27 months. The most common any-grade adverse events were diarrhea, alopecia, and asthenia; the most common grade $\geq 3$ events were neutropenia, febrile neutropenia, and hypertension. There were no cardiac deaths and mean left ventricular ejection fraction was stable over time. Median investigator-assessed progression-free survival was 18.7 months; objective response rate was $75.6 \%$. Conclusions Safety and efficacy with subcutaneous trastuzumab plus intravenous pertuzumab and docetaxel in mBC are consistent with historical evidence of intravenous trastuzumab with this combination. Findings further support subcutaneous administration not affecting safety/efficacy profiles of trastuzumab in HER2-positive BC with increased flexibility in patient care. A fixed-dose combination of pertuzumab and trastuzumab for subcutaneous injection has recently been approved for the treatment of HER2-positive early/mBC, further addressing the increasing relevance of and need for patient-centric treatment strategies.
\end{abstract}

Trial registration NCT02402712

Keywords HER2-positive breast cancer · Metastatic breast cancer · Pertuzumab · Route of administration $\cdot$ Safety . Subcutaneous trastuzumab

\section{Abbreviations}

ADA

AE

ARR

D IV

eBC

Anti-drug antibody

Adverse event

Administration-related reaction

Intravenous docetaxel

Early breast cancer

Alejandro Juárez-Ramiro-Deceased.

Sherko Kuemmel

s.kuemmel@kem-med.com

Extended author information available on the last page of the article
H IV Intravenous trastuzumab

H SC Subcutaneous trastuzumab

HER2 Human epidermal growth factor receptor 2

HR Hazard ratio

LVEF Left ventricular ejection fraction

mBC Metastatic breast cancer

NCI-CTCAE National Cancer Institute's Common Terminology Criteria for Adverse Events

ORR Objective response rate

OS Overall survival

P IV Intravenous pertuzumab

PFS Progression-free survival 
PH FDC SC Fixed-dose combination of pertuzumab and trastuzumab for subcutaneous injection

rHuPH20

\section{Introduction}

In previously untreated patients with human epidermal growth factor receptor 2 (HER2)-positive metastatic breast cancer (mBC), the pivotal phase 3 CLEOPATRA study demonstrated improved progression-free survival (PFS: 18.5 vs. 12.4 months, hazard ratio [HR] $0.62 ; 95 \%$ confidence interval, $0.51-0.75 ; P<0.001$ ), as assessed by an independent review facility, with first-line intravenous fixed-dose pertuzumab (P IV), weight-based intravenous trastuzumab (H IV), and docetaxel (D IV) compared with placebo, H IV, and D IV. Statistical significance for improved overall survival (OS) with P IV plus H IV and D IV was reached in a secondary interim analysis and further confirmed after an additional year (at 30-month follow-up: not reached vs. 37.6 months, HR 0.66; at 4 years' follow-up: 56.5 vs. 40.8 months, HR 0.68) [1-3]. Based on these results, H IV plus P IV and D IV is the first-line standard of care for these patients [4]. The CLEOPATRA end-of-study analysis at 99-month follow-up (maximum 120 months) has continued to show the improved OS benefit of this regimen (57.1 vs. 40.8 months, HR 0.69) and confirmed the consistency of its long-term safety, including maintained cardiac safety, compared with placebo, H IV, and D IV [5].

Despite the benefit of H IV in HER2-positive mBC [6], the current IV formulation involves dose calculations, aseptic preparation of infusion fluids, long infusion durations ( 30-90 $\mathrm{min}$ ), and placement of a central line for administration [7, 8]. Subcutaneous trastuzumab (H SC) contains a fixed dose of $600 \mathrm{mg}$ of $\mathrm{H}$ co-formulated with $2000 \mathrm{U} / \mathrm{m}$ of recombinant human hyaluronidase ( $\mathrm{rHuPH} 20)$, a permeant enhancer that allows absorption and dispersion of large fluid volumes through degradation of hyaluronan [9]. It can be administered in 2-5 min and has been shown to reduce patient chair and active healthcare professional time, compared with H IV (20.9 vs. 77.8 min $[P<0.0001]$ and 5.1 vs. 20.8 min $[P<0.0001]$, respectively) $[8,10]$. In contrast to $\mathrm{H} \mathrm{IV}$, a loading dose and weight-adjusted dose are not required for $\mathrm{H} \mathrm{SC}$. Phase 2 and 3 studies have also reported higher patient preference and healthcare professional satisfaction with H SC compared with H IV, in both HER2positive early breast cancer (eBC) and $\mathrm{mBC}$ (PrefHer and MetaspHer, respectively) [11-13].

In the pivotal phase 3 HannaH study, H SC was noninferior to H IV in patients with HER2-positive eBC, based on co-primary endpoints of pathologic complete response in the breast and serum trough concentration at pre-dose

cycle 8 [14]. Event-free survival and OS, as well as safety, were also shown to be comparable between the two arms [14-17]. SafeHer further supported safety and tolerability of $\mathrm{H} \mathrm{SC}$ as adjuvant therapy with concurrent or sequential chemotherapy for HER2-positive eBC; MetaspHer showed similar results in the metastatic setting [13, 18-20]. SAPPHIRE showed similar safety and tolerability of H SC compared with H IV plus P IV and a taxane in the metastatic setting; however, this was a study of only 50 patients and such results have not yet been demonstrated globally.

Here, we report results from the primary and final analysis of MetaPHER (NCT02402712). To our knowledge, this is the largest study to evaluate safety and tolerability of first-line H SC plus P IV and D IV in patients with HER2-positive mBC.

\section{Materials and methods}

\section{Study design and patients}

MetaPHER was an open-label, single-arm, multicenter, phase $3 \mathrm{~b}$ study. Full details of the study design are provided in the trial protocol in the supplementary materials (Online Resource 1). Eligible patients were aged $\geq 18$ years with histologically or cytologically confirmed HER2-positive mBC previously untreated with systemic non-hormonal anti-cancer therapy. Prior treatment with $\leq 2$ lines of hormonal therapy, one of which could be in combination with everolimus, was permitted. Hormonal therapy concomitant with the use of P IV and H IV was permitted after chemotherapy discontinuation. Additional inclusion criteria included baseline left ventricular ejection fraction (LVEF) $\geq 50 \%$. Key exclusion criteria were prior adjuvant/neoadjuvant treatment with any anti-HER2 agent other than $\mathrm{H}$ for $\mathrm{BC}$, a disease-free interval of $<6$ months from completion of adjuvant/neoadjuvant systemic non-hormonal treatment to recurrence of $\mathrm{BC}$, and radiographic (computer tomography or magnetic resonance imaging) evidence of uncontrolled (symptomatic or requiring treatment with continuous corticosteroids) central nervous system metastases.

\section{Treatment}

All patients received $\geq 1$ dose of $\mathrm{H} \mathrm{SC}$ (fixed-dose $600 \mathrm{mg}$ ) plus P IV (loading dose: $840 \mathrm{mg} / \mathrm{kg}$; maintenance dose: $420 \mathrm{mg} / \mathrm{kg}$ ) every 3 weeks. D IV was also administered every 3 weeks for $\geq 6$ cycles with a recommended initial dose of $75 \mathrm{mg} / \mathrm{m}^{2}$; continuation after cycle 6 was at the discretion of the treating physician and patient. The dose of docetaxel could be escalated to $100 \mathrm{mg} / \mathrm{m}^{2}$ if well tolerated. Granulocyte colony-stimulating factor was used according to product license and approved prescribing information for 
docetaxel and American Society of Clinical Oncology clinical guidelines [21]. Treatment was continued until disease progression, unacceptable toxicity, withdrawal of consent, death, or predefined study end.

\section{Endpoints}

The primary objective was evaluation of safety and tolerability. Adverse events (AEs) and cardiac AEs were graded according to the National Cancer Institute's Common Terminology Criteria for Adverse Events (NCI-CTCAE) version 4.0 [22]. Heart failures were classified according to the New York Heart Association Functional Classification system.

Secondary objectives were evaluation of efficacy (investigator-assessed PFS, OS, and investigator-assessed objective response rate [ORR]) and incidence of anti-H and anti-rHuPH20 antibody formation. Investigator-assessed PFS and ORR were determined using Response Evaluation Criteria In Solid Tumors version 1.1.

\section{Statistics}

The planned sample size was 400 patients. The primary objective was assessed at 24 months after enrollment of the last patient, with analyses performed in all patients who received $\geq 1$ dose of any study drug. The Kaplan-Meier method was used to estimate the medians of PFS and OS. All results are descriptive.

\section{Results}

\section{Patients and treatment exposure}

A total of 418 patients were enrolled in the study at 88 locations across 12 countries (May 6, 2015-February 23, 2017); 412 patients received $\geq 1$ cycle of treatment and were analyzed for safety; median duration of follow-up was 27 months. At the date of clinical cutoff for final analysis (February 22, 2019), 276 patients had completed the study and 160 remained on treatment (Fig. 1).

The mean age of patients was 55.6 years (standard deviation: 11.7) (Online Resource 2). All patients enrolled had HER2-positive disease and most had visceral disease $(n=306[74.3 \%])$ and estrogen receptor- and/or progesterone receptor-positive hormonal status $[n=290$ (70.4\%)]. Approximately half of patients did not receive prior neoadjuvant or adjuvant treatment; 131 patients $(31.8 \%)$ had received prior $\mathrm{H}$ therapy.

The median numbers of cycles for H SC, P IV, and D IV were 22.0, 21.5, and 6.0, respectively. The maximum number of cycles for H SC and P IV was 63; that of D IV was
18. Among the 195 patients who received $\geq 1$ anti-cancer treatment after study treatment discontinuation and disease progression, $160(82.1 \%)$ were treated with HER2-targeted therapies (Online Resource 3). From first cycle onwards, 100 patients $(24.3 \%)$ were treated with prophylactic granulocyte colony-stimulating factor (253 treatments received).

\section{Safety}

A safety overview is provided in Table 1 . Any-grade and grade $\geq 3$ AEs occurred in 406 (98.5\%) and 221 (53.6\%) patients, respectively. The most common any-grade AEs were diarrhea $(n=261[63.3 \%])$, alopecia $(n=193$ [46.8\%]), and asthenia ( $n=137[33.3 \%])$ (Table 2). The most common grade $\geq 3$ AEs were neutropenia $(n=52[12.6 \%])$, febrile neutropenia $(n=35[8.5 \%])$, and hypertension $(n=25$ [6.1\%]) (Table 2). Investigator-reported administrationrelated and local injection site reactions occurred in 87 patients (21.1\%) (Table 2); H SC-related reactions occurred in 21 patients $(5.1 \%)$, and all were grade 1 . Serious AEs were reported in 107 patients (26.0\%), treatment-related AEs in 399 patients $(96.8 \%)$, AEs leading to withdrawal from any study treatment in 87 patients $(21.1 \%$; most frequently withdrawal of D IV $[76 / 87 ; 87.4 \%]$ ), and AEs leading to interruption of any study treatment in 147 patients (35.7\%) (Table 1).

There were 87 deaths $(21.1 \%)$ (Table 1). Most common causes were disease progression $(n=73[17.7 \%])$, AEs $(n=9[2.2 \%])$, and other causes occurring after treatment discontinuation determined to have an "unknown" cause by the investigator ( $n=5[1.2 \%])$. AEs leading to death were "unexplained death" $(n=4)$, aortic dissection, lactic acidosis, community-acquired pneumonia (without neutropenia), B-cell lymphoblastic leukemia, and suicide ( $n=1$ each).

Three patients $(0.7 \%)$ had grade $\geq 3$ cardiac AEs (Table 1), which were supraventricular tachycardia $(n=1)$ and left ventricular dysfunction $(n=2)$. Serious AEs suggestive of congestive heart failure occurred in one patient $(0.2 \%)$ (Table 1$)$ in the form of left ventricular dysfunction; there were no cardiac deaths (Table 1). Mean LVEF was stable over time (Online Resource 4), with decreases at cycles 60 and 63 and during safety follow-up at weeks 120 and 144; notably, small numbers of patients were assessed at these timepoints. Table 3 provides a summary of significant LVEF declines (reduction of $\geq 10 \%$ from baseline to LVEF $<50 \%$ ). Median baseline LVEF was $64 \%$ and median post-baseline worst LVEF was $58 \%$. Of the 396 patients with LVEF measurements at baseline and $\geq 1$ post-baseline visit, $40(10.1 \%)$ had a significant LVEF drop.

Patients were also analyzed by hormone receptor status and treatment with hormonal therapy. The most common any-grade AEs for patients with hormone receptor-positive BC who received hormonal therapy were diarrhea $(n=83$ 
Fig. 1 Patient dispositions. $H$ SC subcutaneous trastuzumab, FUP follow-up period, $P I V$ intravenous pertuzumab, $P S P$ patient support program, $P T A P$ post-trial access program, SoC standard of care

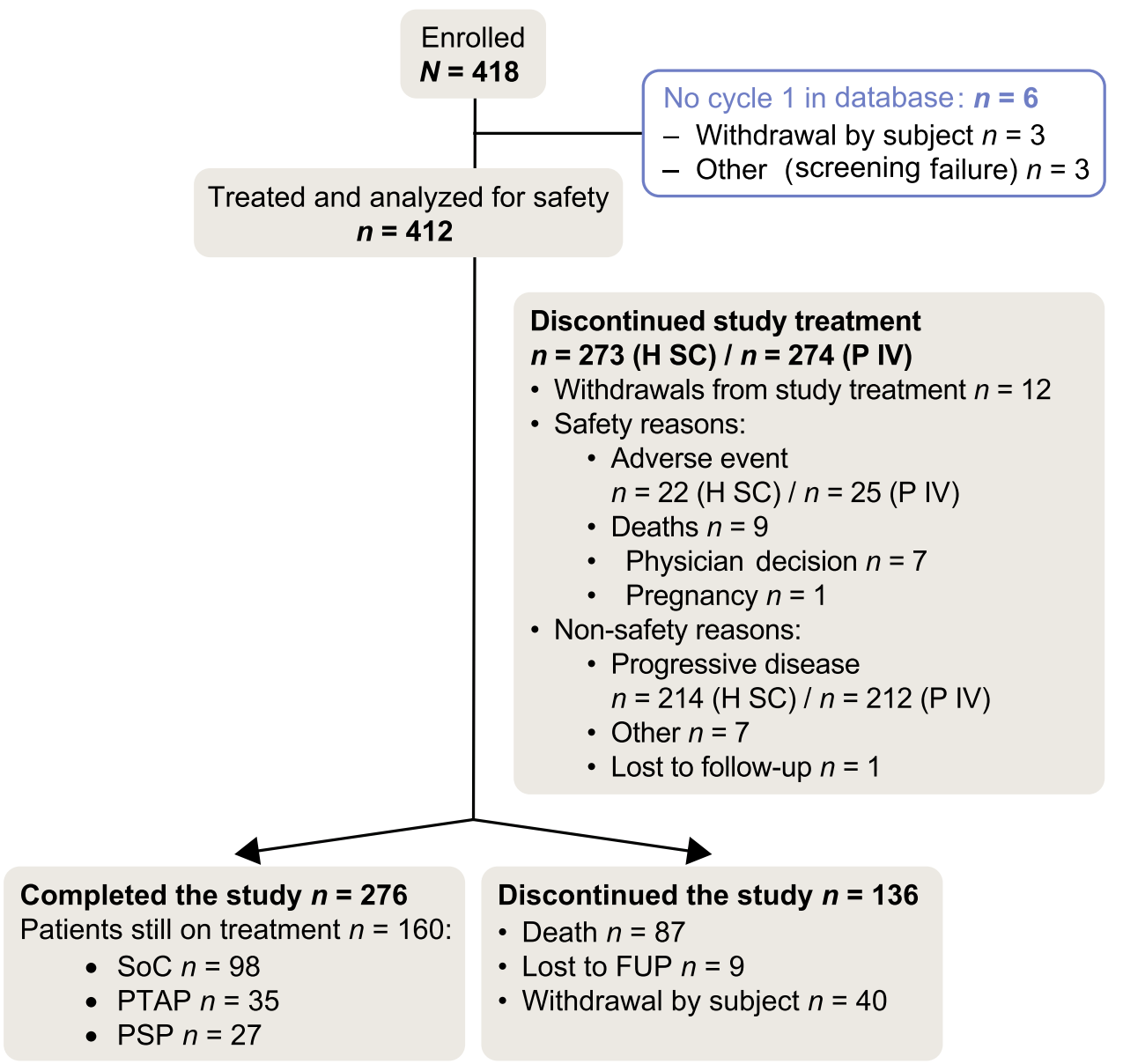

[64.8\%]), alopecia $(n=59[46.1 \%])$, and asthenia $(n=48$ [37.5\%]). The most common grade $\geq 3$ events for the same subgroup were febrile neutropenia ( $n=16$ [12.5\%]), neutropenia $(n=13[10.2 \%])$, and diarrhea $(n=9[7.0 \%])$. In both cases, this was found not to differ from patients with hormone receptor-positive $\mathrm{BC}$ who did not receive hormonal therapy. Patients with hormone receptor-positive $\mathrm{BC}$ that received $\geq 1$ dose of $\mathrm{H}$ IV/P IV after D IV discontinuation showed a low incidence of grade $\geq 3$ events that also did not differ depending on hormonal therapy.

\section{Efficacy}

Median investigator-assessed PFS was 18.7 months (234 events [56.8\%]) (Fig. 2a). Median OS was not reached by study end ( 87 events [21.1\%]), and OS rates at 12 and 24 months were $92.89 \%$ and $81.13 \%$, respectively (Fig. 2b). ORR was 75.6\%; 42 (12.5\%) and $212(63.1 \%)$ patients achieved a complete and partial response, respectively (Online Resource 5). The clinical benefit rate was 92.0\% (309 patients). At 2 years, investigator-assessed PFS was greater for those given hormonal therapy compared with those that were not (55 events [53.8\%] vs. 99 events [33.2\%]).

\section{Anti-drug antibodies for H SC}

Fifty-six (14.1\%) and 95 (24.0\%) patients were positive for anti-drug antibodies (ADAs) at baseline and post-baseline, respectively (Online Resource 6). Of the 95 patients with post-baseline ADAs, these were treatment-induced in 82 and treatment-enhanced in $13 ; 42 / 82$ patients with treatmentinduced ADAs had transient ADAs, while 40 had persistent ADAs. The median time to ADA onset was 3 weeks, and titers ranged from 1.00 to 512.00 . Two patients $(2.1 \%)$ had administration-related reactions (ARRs), both were $\mathrm{H}$ SC-related and occurred within $24 \mathrm{~h}$ of administration. Seventeen of the 300 patients who were ADA-negative postbaseline $(5.7 \%)$ also had ARRs. In both cases, no patients experienced ARRs grade $\geq 3$.

Anti-rHuPH20 antibodies post-baseline were observed in $11 / 396$ patients. 
Table 1 Safety summary

\begin{tabular}{ll}
\hline & $\begin{array}{l}\text { H SC +P IV + D IV } \\
(N=412)\end{array}$ \\
\hline Any AE & $406(98.5)$ \\
Grade $\geq 3$ AE & $221(53.6)$ \\
Serious AE & $107(26.0)$ \\
Death & $87(21.1)$ \\
Death due to disease progression & $73(17.7)$ \\
Death due to AEs & $9(2.2)$ \\
Death due to other causes & $5(1.2)$ \\
Related AE & $399(96.8)$ \\
AE leading to drug withdrawal & \\
AE leading to drug interruption & a \\
Cardiac AE & $87(21.1)$ \\
Grade $\geq 3$ cardiac AE $^{\mathrm{b}}$ & $147(35.7)$ \\
Serious AE suggestive of $\mathrm{CHF}^{\mathrm{c}}$ & \\
Cardiac death $^{\mathrm{d}}$ & $3(0.7)$ \\
\hline
\end{tabular}

${ }^{a}$ Any event related to any study treatment component (H SC, P IV, or D IV)

bEvents classified as System Organ Class "Cardiac Disorders"

"Serious events classified using the SMQ "Cardiac Failure"

${ }^{\mathrm{d}}$ Deaths with SOC Cardiac Disorders as the primary cause

$A E$ adverse event, $C H F$ congestive heart failure, $D I V$ intravenous docetaxel, $H S C$ subcutaneous trastuzumab, $P I V$ intravenous pertuzumab, $S M Q$ Standardized MedDRA Query

Data are number of patients (\%)

\section{Discussion}

In this primary and final analysis of 412 patients with HER2-positive $\mathrm{mBC}$, the safety profile of first-line H SC plus P IV and D IV was tolerable and consistent with that of CLEOPATRA, in which $\mathrm{H}$ was delivered intravenously within the same combination regimen and in a similar patient population $[1-3,5]$. No new safety signals were identified and AEs of particular interest to $\mathrm{P}+\mathrm{H}$ therapy, including diarrhea, rash, mucosal inflammation, and febrile neutropenia, occurred less frequently in MetaPHER than in the CLEOPATRA secondary interim OS analysis [2]. The incidence of AEs was similar whether patients received additional hormone therapy or not, with diarrhea and febrile neutropenia the most common any-grade and grade $\geq 3$ events, respectively.

Cardiac safety was further assessed in MetaPHER. Although grade $\geq 3$ cardiac AEs and serious AEs suggestive of congestive heart failure were more frequent in the CLEOPATRA secondary analysis, no cardiac deaths were reported in either study [2]. Baseline and post-treatment median LVEFs were also similar. Although a higher proportion of patients had significant LVEF declines in MetaPHER, the majority of events were grade 1 or 2 and asymptomatic, and did not lead to study drug discontinuation.

Though efficacy results here were exploratory, investigator-assessed PFS and ORR findings support results observed with first-line H IV plus P IV and D IV in CLEOPATRA [2]. Median PFS was 18.7 months in MetaPHER and the CLEOPATRA secondary analysis [2]; ORRs were also
Table 2 Any-grade and grade $\geq 3$ AEs and investigatorreported AEs

\begin{tabular}{|c|c|c|}
\hline & \multicolumn{2}{|c|}{$\begin{array}{l}\mathrm{H} \mathrm{SC}+\mathrm{P} \text { IV + D IV } \\
(N=412)\end{array}$} \\
\hline & Any grade & Grade $\geq 3$ \\
\hline \multicolumn{3}{|l|}{$\mathrm{AE}$} \\
\hline Leukopenia & $29(7.0)$ & $15(3.6)$ \\
\hline Febrile neutropenia & $35(8.5)$ & $35(8.5)$ \\
\hline Neutropenia & $75(18.2)$ & $52(12.6)$ \\
\hline Diarrhea & $261(63.3)$ & $21(5.1)$ \\
\hline Mucositis & $68(16.5)$ & $3(0.7)$ \\
\hline Interstitial lung disease & $5(1.2)$ & $1(0.2)$ \\
\hline Rash & $68(16.5)$ & $4(1.0)$ \\
\hline Hypersensitivity, anaphylaxis & $1(0.2)$ & $1(0.2)$ \\
\hline \multicolumn{3}{|l|}{ Investigator-reported AE } \\
\hline ARR and local injection site reactions & $87(21.1)$ & $5(1.2)$ \\
\hline ARR and local injection site reactions: Only H SC-related & $21(5.1)$ & 0 \\
\hline ARR and local infusion site reactions: Only P IV infusion-related & $22(5.3)$ & $1(0.2)$ \\
\hline ARR and local infusion site reactions: Only D IV infusion-related & $48(11.7)$ & $4(1.0)$ \\
\hline
\end{tabular}

$A E$ adverse event, $A R R$ administration-related reactions, $D I V$ intravenous docetaxel, $H S C$ subcutaneous trastuzumab, $P I V$ intravenous pertuzumab

Data are number of patients $(\%)$ 
Table 3 Summary of significant LVEF declines, overall and by treatment phase

\begin{tabular}{|c|c|c|c|}
\hline & \multicolumn{3}{|c|}{$\mathrm{H} \mathrm{SC}+\mathrm{P}$ IV + D IV } \\
\hline & $\begin{array}{l}\text { Overall } \\
(N=412)\end{array}$ & $\begin{array}{l}\text { Treatment phase } \\
(n=387)\end{array}$ & $\begin{array}{l}\text { Post-treatment } \\
\text { phase } \\
(n=387)\end{array}$ \\
\hline Median baseline LVEF (range) & $64(50-83)^{\mathrm{a}}$ & & \\
\hline Median overall post-baseline worst value (range) & $58(30-74)^{\mathrm{b}}$ & $59.0(30-74)$ & $60.0(34-75)$ \\
\hline \multicolumn{4}{|l|}{ Patients with baseline and $\geq 1$ post-baseline value measured } \\
\hline Increase or no change & $89(22.5)^{\mathrm{c}}$ & $93(24.2)^{\mathrm{d}}$ & $65(40.1)^{\mathrm{e}}$ \\
\hline Decrease of $<10 \%$ points from baseline & $182(46.0)^{\mathrm{c}}$ & $178(46.2)^{\mathrm{d}}$ & $61(37.7)^{\mathrm{e}}$ \\
\hline Decrease of $\geq 10 \%$ points from baseline & $125(31.6)^{\mathrm{c}}$ & $114(29.6)^{\mathrm{d}}$ & $36(22.2)^{\mathrm{e}}$ \\
\hline Patients with LVEF $<50 \%$ and decrease $\geq 10 \%$ points from baseline & $40(10.1)^{\mathrm{c}}$ & $37(9.6)$ & $13(8.0)$ \\
\hline LVEF $45 \%-50 \%$ and decreased $\geq 10 \%$ points from baseline & $21(5.3)^{\mathrm{c}}$ & $21(5.5)$ & $4(2.5)$ \\
\hline LVEF $<45 \%$ and decreased $\geq 10 \%$ points from baseline & $22(5.6)^{\mathrm{c}}$ & 19 (4.9) & $9(5.6)$ \\
\hline
\end{tabular}

${ }^{\mathrm{a}} n=411$

$\mathrm{b}_{n}=398$

${ }^{\mathrm{c}} n=396$

${ }^{\mathrm{d}} n=385$

${ }^{\mathrm{e}} n=162$

$A E$ adverse event, $D I V$ intravenous docetaxel, $H S C$ subcutaneous trastuzumab, $L V E F$ left ventricular ejection fraction, $P I V$ intravenous pertuzumab

Data are median (range) or number of patients (\%)

similar, although the number of patients achieving complete response was slightly higher in CLEOPATRA vs. MetaPHER [1, 2].

The incidence of post-treatment ADAs to H SC (24\%) was higher in MetaPHER than in HannaH (14.9\%) [14]; pre-existing ADAs from previous H IV treatment at baseline or increased anti-framework antibodies from $\mathrm{H}+\mathrm{P}$ may explain this. Analysis of safety by immunogenicity status indicated no noticeable association between the presence of treatment-emergent ADAs for $\mathrm{H} \mathrm{SC}$ and increased frequency or severity of ARRs.

Despite MetaPHER and CLEOPATRA including similar numbers of de novo patients with no prior therapy for BC ( $n=205$ [49.8\%] and $n=218$ [54.2\%], respectively), the proportion who received $\mathrm{H}$ treatment prior was higher in our study ( $n=131$ [31.8\%] vs. $n=47$ [11.7\%]) [1]. This is reflective of the fact that when the CLEOPATRA study design was developed, use of $\mathrm{H}$ as adjuvant treatment for $\mathrm{BC}$ was not as common. Race/ethnic group also differed between CLEOPATRA and our study, with MetaPHER including fewer Asians ( $n=2[0.5 \%]$ vs. $n=125$ [31.1\%]) and more White individuals $(n=347$ [84.2\%] vs. $n=245$ [60.9\%]). These differences, as well as differences in study design/procedures (e.g., different versions of NCI-CTCAE for AE grading, and MetaPHER permitting concomitant use of hormonal therapy with study drug and excluding patients with disease-free interval of $<6$ months vs. 12 months for
CLEOPATRA), reflect differences in scope and timing of this study vs. CLEOPATRA [1].

The findings from the present study further add to the body of evidence indicating that SC administration does not affect the safety and efficacy profiles of $\mathrm{H}$ in HER2-positive BC. In particular, results from MetaPHER further confirm that a bridging approach based on pharmacokinetics is effective in the development of SC formulations of monoclonal antibodies. In specific circumstances, it may allow extrapolation of data across indications in a regimen-agnostic manner, which could save time and resources in the development of future SC formulations. In fact, the HannaH study first demonstrated that $\mathrm{H}$ SC had non-inferior drug exposure compared to H IV, as well as non-inferior efficacy and comparable safety, in the neoadjuvant setting and in combination with chemotherapy in patients with HER2-positive eBC [14-17]. Based on the known efficacy, safety, and pharmacokinetic similarities of $\mathrm{H} \mathrm{IV}$ across $\mathrm{eBC}$ and $\mathrm{mBC}$ and the consistent role of HER2 overexpression in driving tumor growth across the HER2 spectrum, the consistent results from MetaPHER of $\mathrm{H} \mathrm{SC}$ in $\mathrm{mBC}$ and in combination with a P-based regimen were not surprising.

The relevance of SC formulations for patients and physicians is increasing and opportunities for more flexible care outside of the traditional hospital setting are emerging. In that regard, H SC has demonstrated an acceptable safety profile both when administered in the hospital and at home [23], 

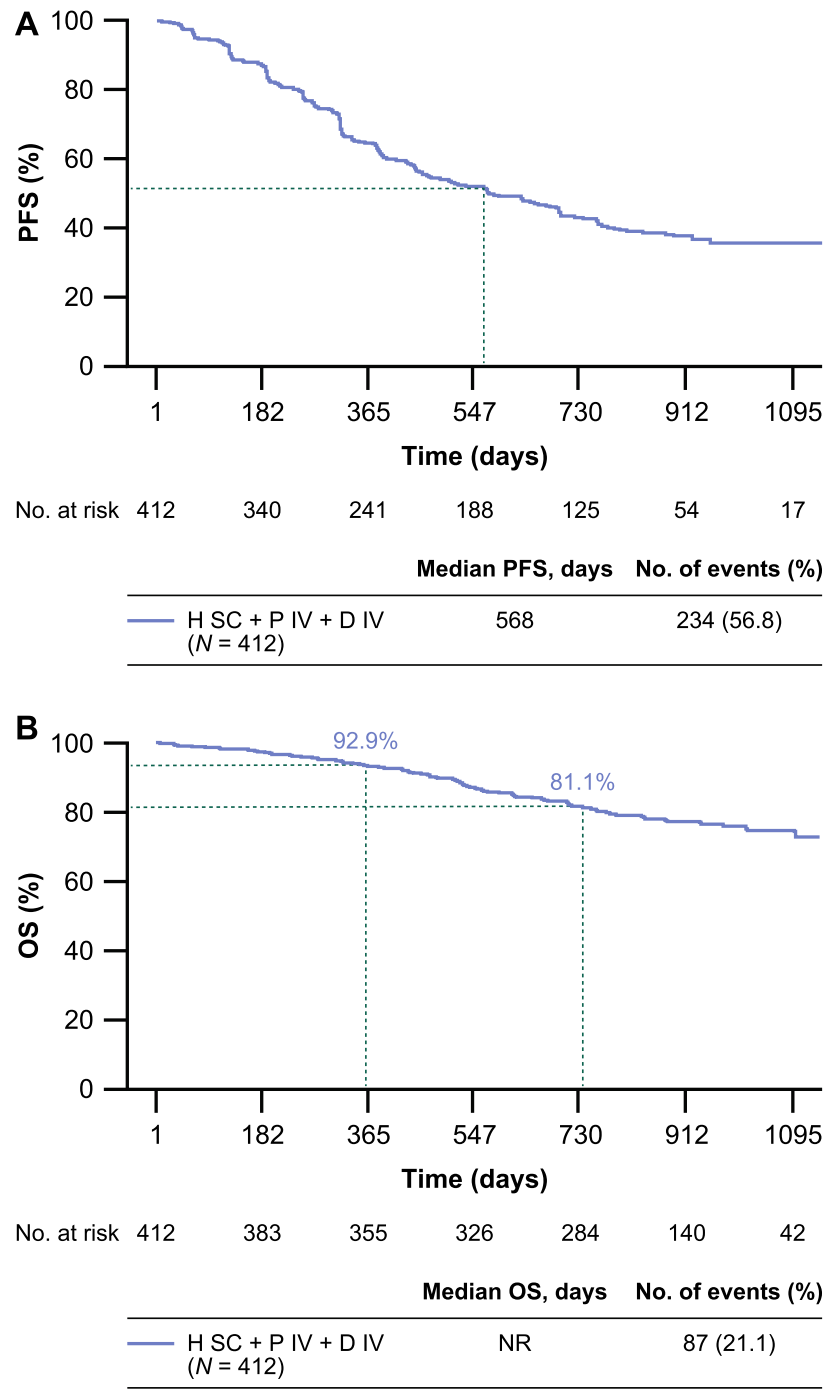

Fig. 2 Investigator-assessed PFS and OS. a, investigator-assessed PFS. b, OS. D IV intravenous docetaxel, $H S C$ subcutaneous trastuzumab, $N R$ not reported, $O S$ overall survival, $P I V$ intravenous pertuzumab, $P F S$ progression-free survival

and a public/private partnership in Italy (HERHOME) has recently been initiated to deliver H SC therapy in a patients' home [24-26]. A fixed-dose combination of $\mathrm{P}+\mathrm{H}$ for SC injection (PH FDC SC) has been recently approved by the US Food and Drug Administration and European Medicines Agency for the treatment of patients with HER2-positive eBC and $\mathrm{mBC}$ [27, 28], based on the demonstration of non-inferior pre-dose cycle $8 \mathrm{P}$ and $\mathrm{H}$ serum trough concentration and comparable efficacy and safety to the IV formulations in patients with HER2-positive eBC [29]. PH FDC SC provides increased flexibility in patient care than $\mathrm{H} \mathrm{SC}$ as both $\mathrm{H}$ and $\mathrm{P}$ can be administered subcutaneously in minutes rather than hours. Similar benefits to H SC vs. H $\mathrm{IV}$, including reduced patient clinic time, improved comfort during administration, and greater patient preference, were also reported with PH FDC SC [30].

\section{Conclusions}

As MetaPHER was a single-arm study, no comparator arm is available for direct comparisons of H SC plus P IV and D IV with H IV plus P IV and D IV. However, safety and efficacy results from this large cohort of patients with HER2-positive $\mathrm{mBC}$ in our study are consistent with the results of $\mathrm{H} \mathrm{IV}$ plus P IV and D IV in CLEOPATRA and further support the conclusion of the pivotal HannaH study for $\mathrm{H} \mathrm{SC}$ in eBC [1-3, 5, 14]. Together, these results indicate that efficacy and safety of $\mathrm{H}$ given within standard regimens including $\mathrm{P}$ for HER2-positive eBC and $\mathrm{mBC}$ are not affected by administration route. Results in the present study also complement evidence of increased flexibility of $\mathrm{H} \mathrm{SC}$ to patients with $\mathrm{BC}$, shortening administration time, and reducing patient clinic time. This novel route of administration of $\mathrm{H}$ is the first step in taking patients with HER2-positive BC to the next level of treatment convenience, opening the door to homecare therapy options.

Supplementary Information The online version contains supplementary material available at https://doi.org/10.1007/s10549-021-06145-3.

Acknowledgements The sponsor, F. Hoffmann-La Roche Ltd, Basel, Switzerland, contributed to the design of this study. Data collected by the investigators were analyzed by statisticians at F. Hoffmann-La Roche Ltd. Authors employed by the study sponsor contributed to the conduct of the study; collection, management, analysis, and interpretation of the data; and preparation, review, and approval of the manuscript, as well as the decision to submit the manuscript for publication. We would also like to thank all volunteers, patients, and other investigators who participated in this study. Support for third-party writing assistance for this manuscript, furnished by Katie Wilson, $\mathrm{PhD}$, and Stephen Salem, BSc, of Health Interactions, was provided by F. Hoffmann-La Roche Ltd.

Author contributions All authors had full access to all the data in the study and take responsibility for the integrity of the data and the accuracy of the data analysis. Study concept and design: SK, CAT, JA, BK, AJR, SCH, EM, MS, ER. Acquisition, analysis, or interpretation of data: SK, CAT, JA, ZN, EH, BK, AJR, FMV, JMPG, SCH, EM, MS, ER, MB, MM. Drafting of the manuscript: SK, SCH, EM, ER, MM. Critical revision of the manuscript for important intellectual content: All authors. Statistical analysis/quality control of data and algorithms: BK, JMPG, MS, MM.

Funding This study was sponsored by F. Hoffmann-La Roche Ltd.

Data availability Qualified researchers may request access to individual patient level data through the clinical study data request platform (https://vivli.org/). Further details on Roche's criteria for eligible studies are available here: https://vivli.org/members/ourmembers/. For further details on Roche's Global Policy on the Sharing of Clinical Information and how to request access to related clinical study documents, see here: https://www.roche.com/research_and_development/ 
who_we_are_how_we_work/clinical_trials/our_commitment_to_data_ sharing.htm

\section{Compliance with ethical standards}

Conflict of interest All authors received support for third-party writing assistance for this manuscript, provided by F. Hoffmann-La Roche Ltd. Professor Kümmel has received consulting fees from F. Hoffmann-La Roche Ltd, Genomic Health, Novartis, Amgen, Celgene, Daiichi Sankyo, AstraZeneca, Somatex, Merck Sharp \& Dohme, Pfizer, PUMA Biotechnology, and PFM Medical, and has received non-financial support outside the submitted work for a travel grant from F. Hoffmann-La Roche Ltd, Daiichi Sankyo, and SonoScape. Dr. Tondini has received an institutional grant from ASST Papa Giovanni XXIII for participation in the MetaPHER study, and institutional grants for participation in other clinical trials from F. Hoffmann-La Roche Ltd, Novartis, Merck Sharp \& Dohme, Bristol Myers Squibb, AstraZeneca, and Array BioPharma, Inc. Dr. Abraham has received personal fees for conference participation from Eisai, and personal fees for an advisory board from Merck \& Co, Inc. Dr. Nowecki has received a travel grant from F. Hoffmann-La Roche Ltd. Dr. Itrych has no other conflicts to disclose. Dr. Hitre has received research funding and non-financial support (i.e., drugs) outside the submitted work from F. Hoffmann-La Roche Ltd. Dr. Karaszewska has received research grants from F. Hoffmann-La Roche Ltd, Novartis, Merck \& Co, Inc., and Amgen. Dr. Juárez-Ramiro has received fees for clinical research from F. Hoffmann-La Roche Ltd, Bristol Myers Squibb, Merck Sharp \& Dohme, Bayer, Pfizer, and Amgen, and personal speaker fees from F. Hoffmann-La Roche Ltd, Bristol Myers Squibb, Merck Serono, Bayer, and Amgen. Dr. MoralesVásquez has received consulting fees from F. Hoffmann-La Roche Ltd, AstraZeneca, and Asofarma. Dr. Pérez García has received personal fees for an advisory board and travel grants from F. HoffmannLa Roche Ltd, and has received personal fees for an advisory board from Lilly. Dr. Cardona-Huerta has received consulting fees from F. Hoffmann-La Roche Ltd and AstraZeneca. Dr. Monturus is an employee of F. Hoffmann-La Roche Ltd (author and spouse/partner) and has stock/ownership interest in F. Hoffmann-La Roche Ltd/Genentech, Inc. (author and spouse/partner). Dr. Sequi is an employee of PAREXEL and is contracted by F. Hoffmann-La Roche Ltd. Dr. Restuccia is an employee of F. Hoffmann-La Roche Ltd and has stock/ownership interest in F. Hoffmann-La Roche Ltd. Dr. Benyunes is an employee of Genentech, Inc. Dr. Martín has received research grants and personal fees from F. Hoffmann-La Roche Ltd, PUMA, and Novartis, consulting/advisory fees from AstraZeneca, Amgen, Taiho Oncology, F. Hoffmann-La Roche Ltd/Genentech, Inc., Novartis, PharmaMar, Eli Lilly, PUMA, Daiichi Sankyo, and Pfizer.

Ethical approval The study was performed in accordance with the Declaration of Helsinki and Good Clinical Practice guidelines. Approval for the study protocol and all accompanying material provided to patients was obtained from independent ethics committees at participating institutions.

Consent to participate All patients provided written informed consent.

Open Access This article is licensed under a Creative Commons Attribution 4.0 International License, which permits use, sharing, adaptation, distribution and reproduction in any medium or format, as long as you give appropriate credit to the original author(s) and the source, provide a link to the Creative Commons licence, and indicate if changes were made. The images or other third party material in this article are included in the article's Creative Commons licence, unless indicated otherwise in a credit line to the material. If material is not included in the article's Creative Commons licence and your intended use is not permitted by statutory regulation or exceeds the permitted use, you will need to obtain permission directly from the copyright holder. To view a copy of this licence, visit http://creativecommons.org/licenses/by/4.0/.

\section{References}

1. Baselga J, Cortés J, Kim SB, Im SA, Hegg R, Im YH, Roman L, Pedrini JL, Pienkowski T, Knott A, Clark E, Benyunes MC, Ross G, Swain SM (2012) CLEOPATRA Study Group Pertuzumab plus trastuzumab plus docetaxel for metastatic breast cancer. N Engl J Med 366:109-119. https://doi.org/10.1056/NEJMoa1113216

2. Swain SM, Kim S-B, Cortés J, Ro J, Semiglazov V, Campone M, Ciruelos E, Ferrero J-M, Schneeweiss A, Knott A, Clark E, Ross G, Benyunes MC, Baselga J (2013) Pertuzumab, trastuzumab, and docetaxel for HER2-positive metastatic breast cancer (CLEOPATRA study): Overall survival results from a randomised, double-blind, placebo-controlled, phase 3 study. Lancet Oncol 14:461-471. https://doi.org/10.1016/S1470-2045(13) 70130-X

3. Swain SM, Baselga J, Kim SB, Ro J, Semiglazov V, Campone M, Ciruelos E, Ferrero JM, Schneeweiss A, Heeson S, Clark E, Ross G, Benyunes MC, Cortes J, CLEOPATRA Study Group (2015) Pertuzumab, trastuzumab, and docetaxel in HER2-positive metastatic breast cancer. N Engl J Med 372:724-734. https://doi.org/ 10.1056/NEJMoa1413513

4. National Comprehensive Cancer Network (NCCN) (2020) NCCN Clinical Practice Guidelines in Oncology (NCCN Guidelines ${ }^{\circledR}$ ): Breast Cancer. Version 4. 2020. https://www.nccn. org/professionals/physician_gls/pdf/breast.pdf. Accessed November 2020

5. Swain SM, Miles D, Kim SB, Im YH, Im SA, Semiglazov V, Ciruelos E, Schneeweiss A, Loi S, Monturus E, Clark E, Knott A, Restuccia E, Benyunes MC, Cortés J, CLEOPATRA study group (2020) Pertuzumab, trastuzumab, and docetaxel for HER2-positive metastatic breast cancer (CLEOPATRA): end-of-study results from a double-blind, randomised, placebo-controlled, phase 3 study. Lancet Oncol 21:519-530. https://doi.org/10.1016/s14702045(19)30863-0

6. Slamon DJ, Leyland-Jones B, Shak S, Fuchs H, Paton V, Bajamonde A, Fleming T, Eiermann W, Wolter J, Pegram M, Baselga J, Norton L (2001) Use of chemotherapy plus a monoclonal antibody against HER2 for metastatic breast cancer that overexpresses HER2. N Engl J Med 344:783-792. https://doi.org/10. 1056/NEJM200103153441101

7. Dent S, Ammendolea C, Christofides A, Edwards S, Incekol D, Pourmirza B, Kfoury S, Poirier B (2019) A multidisciplinary perspective on the subcutaneous administration of trastuzumab in HER2-positive breast cancer. Curr Oncol 26:e70-e80

8. Roche Registration Ltd Herceptin ${ }^{\circledR}$ (trastuzumab). Summary of Product Characteristics. https://www.ema.europa.eu/en/docum ents/product-information/herceptin-epar-product-information en.pdf. Accessed 30 March 2020

9. Bookbinder LH, Hofer A, Haller MF, Zepeda ML, Keller GA, Lim JE, Edgington TS, Shepard HM, Patton JS, Frost GI (2006) A recombinant human enzyme for enhanced interstitial transport of therapeutics. J Control Release 114:230-241. https://doi.org/ 10.1016/j.jconrel.2006.05.027

10. De Cock E, Pivot X, Hauser N, Verma S, Kritikou P, Millar D, Knoop A (2016) A time and motion study of subcutaneous versus intravenous trastuzumab in patients with HER2-positive early breast cancer. Cancer Med 5:389-397

11. Pivot X, Gligorov J, Müller V, Barrett-Lee P, Verma S, Knoop A, Curigliano G, Semiglazov V, Lopez-Vivanco G, Jenkins V, 
Scotto N, Osborne S, Fallowfield L, PrefHer Study Group (2013) Preference for subcutaneous or intravenous administration of trastuzumab in patients with HER2-positive early breast cancer (PrefHer): An open-label randomised study. Lancet Oncol 14:962-970. https://doi.org/10.1016/s1470-2045(13)70383-8

12. Pivot X, Gligorov J, Müller V, Curigliano G, Knoop A, Verma S, Jenkins V, Scotto N, Osborne S, Fallowfield L, PrefHer Study Group (2014) Patients' preferences for subcutaneous trastuzumab versus conventional intravenous infusion for the adjuvant treatment of HER2-positive early breast cancer: Final analysis of 488 patients in the international, randomized, two-cohort PrefHer study. Ann Oncol 25:1979-1987

13. Pivot X, Spano JP, Espie M, Cottu P, Jouannaud C, Pottier V, Moreau L, Extra JM, Lortholary A, Rivera P, Spaeth D, AttarRabia H, Benkanoun C, Dima-Martinez L, Esposito N, Gligorov J (2017) Patients' preference of trastuzumab administration (subcutaneous versus intravenous) in HER2-positive metastatic breast cancer: Results of the randomised MetaspHer study. Eur J Cancer $82: 230-236$

14. Ismael G, Hegg R, Muehlbauer S, Heinzmann D, Lum B, Kim SB, Pienkowski T, Lichinitser M, Semiglazov V, Melichar B, Jackisch C (2012) Subcutaneous versus intravenous administration of (neo) adjuvant trastuzumab in patients with HER2-positive, clinical stage I-III breast cancer (HannaH study): a phase 3, open-label, multicentre randomised trial. Lancet Oncol 13:869-878

15. Jackisch C, Kim SB, Semiglazov V, Melichar B, Pivot X, Hillenbach C, Stroyakovskiy D, Lum BL, Elliott R, Weber HA, Ismael G (2015) Subcutaneous versus intravenous formulation of trastuzumab for HER2-positive early breast cancer: updated results from the phase III HannaH study. Ann Oncol 26:320-325. https:// doi.org/10.1093/annonc/mdu524

16. Jackisch C, Hegg R, Stroyakovskiy D, Ahn JS, Melichar B, Chen SC, Kim SB, Lichinitser M, Staroslawska E, Kunz G, Falcon S, Chen ST, Crepelle-Flechais A, Heinzmann D, Shing M, Pivot X (2016) HannaH phase III randomised study: Association of total pathological complete response with event-free survival in HER2-positive early breast cancer treated with neoadjuvantadjuvant trastuzumab after 2 years of treatment-free follow-up. Eur J Cancer 62:62-75

17. Jackisch C, Stroyakovskiy D, Pivot X, Ahn JS, Melichar B, Chen S-C, Meyenberg C, Al-Sakaff N, Heinzmann D, Hegg R (2019) Subcutaneous vs intravenous trastuzumab for patients with ERBB2-positive early breast cancer: Final analysis of the HannaH phase 3 randomized clinical trial. JAMA Oncol. https://doi. org/10.1001/jamaoncol.2019.0339

18. Gligorov J, Ataseven B, Verrill M, De Laurentiis M, Jung KH, Azim HA, Al-Sakaff N, Lauer S, Shing M, Pivot X, SafeHer Study Group (2017) Safety and tolerability of subcutaneous trastuzumab for the adjuvant treatment of human epidermal growth factor receptor 2-positive early breast cancer: SafeHer phase III study's primary analysis of 2573 patients. Eur J Cancer 82:237-246

19. Jung KH, Ataseven B, Verrill M, Pivot X, De Laurentiis M, AlSakaff N, Lauer S, Shing M, Gligorov J, Azim HA (2018) Adjuvant subcutaneous trastuzumab for HER2-positive early breast cancer: Subgroup analyses of safety and active medical conditions by body weight in the SafeHer phase III study. Oncologist 23:1137-1143. https://doi.org/10.1634/theoncologist.2018-0065

20. Woodward N, De Boer RH, Redfern A, White M, Young J, Truman M, Beith J (2019) Results from the first multicenter, openlabel, phase IIIb study investigating the combination of pertuzumab with subcutaneous trastuzumab and a taxane in patients with HER2-positive metastatic breast cancer (SAPPHIRE). Clin Breast Cancer 19:216-224. https://doi.org/10.1016/j.clbc.2019. 02.008
21. Smith TJ, Bohlke K, Armitage JO (2015) Recommendations for the use of white blood cell growth factors: American Society of Clinical Oncology clinical practice guideline update. J Oncol Pract 11:511-513

22. National Cancer Institute (2009) Common Terminology Criteria for Adverse Events (CTCAE), Version 4.0. https://ctep. cancer.gov/protocolDevelopment/electronic_applications/docs/ CTCAE_4.03.xlsx. Accessed 30 March 2020

23. ten Tije AJ, van Steenis S, Briers J, Elsten EMP (2020) Safety and tolerability of subcutaneous trastuzumab (H SC) self-administered at home via single-use injection device (SID) in patients (pts) with HER2-positive early breast cancer (EBC): Primary and final analysis of the open-label, phase IIIB HOMERUS study. Ann Oncol 31:S303-S339

24. APM Health Europe (2020) Treating patients at home with subcutaneous injections of Roche's Herceptin Hyclecta saves money [press review]. 31 January, 2020. https://www.apmhealtheurope. com/freestory/0/67360/treating-patients-at-home-with-subcutaneo us-injections-of-roche-s-herceptin-hylecta-saves-money. Accessed November 2020

25. Scienza e Farmaci (2020) Tumore al seno. Al Pascale di Napoli, la terapia arriva al domicilio. La prima volta in Italia. http://www. quotidianosanita.it/stampa_articolo.php?articolo_id=80578. Accessed November 2020

26. Corriere Del Mezzogiorno (2020) Tumore al seno, il Pascale avvia la terapia domiciliare. Corriere del mexxogiorno. https:// corrieredelmezzogiorno.corriere.it/napoli/salute/20_gennaio_23/ tumore-seno-pascale-avvia-terapia-domiciliare-79a40330-3dfd11ea-a05f-1ddcfc2c0b77.shtml. Accessed 6 May 2020

27. Food and Drug Administration (FDA) (2020) Phesgo® (pertuzumab, trastuzumab, and hyaluronidase-zzxf). Prescribing Information. https://www.accessdata.fda.gov/drugsatfda_docs/label/ 2020/761170s0001bl.pdf. Accessed November 2020

28. European Medicines Agency (EMA) (2020) Phesgo (pertuzumab, trastuzumab, and hyaluronidase-zzxf). Summary of Product Characteristics. https://www.ema.europa.eu/en/documents/productinformation/phesgo-epar-product-information_en.pdf. Accessed Mar 2021

29. Tan AR, Im S-A, Mattar A, Colomer R, Stroyakovskii D, Nowecki Z, De Laurentiis M, Pierga J-Y, Jung KH, Schem C, Heeson S, Shivhare M, Kirschbrown WP, Restuccia E, Crnjevic TB, Jackisch C (2020) Subcutaneous administration of the fixed-dose combination of trastuzumab and pertuzumab in combination with chemotherapy in HER2-positive early breast cancer: Primary analysis of the phase III, multicenter, randomized, open-label, two-arm FeDeriCa study. Cancer Res. https://doi.org/10.1158/1538-7445. SABCS19-PD4-07

30. O'Shaughnessy J, Sousa S, Cruz J, Fallowfield L, Auvinen P, Pulido C, Cvetanovic A, Wilks S, Ribeiro L, Burotto M, Klingbeil D, Messeri D, Alexandrou A, Trask P, Fredrickson J, Machackova Z, Stamatovic L (2020) Patient (pt) preference for the pertuzumab-trastuzumab fixed-dose combination for subcutaneous use (PH FDC SC) in HER2-positive early breast cancer (EBC): Primary analysis of the open-label, randomised crossover PHranceSCa study 165MO. Ann Oncol. https://doi.org/10.1016/annonc/ annonc 267

Publisher's Note Springer Nature remains neutral with regard to jurisdictional claims in published maps and institutional affiliations. 


\section{Authors and Affiliations}

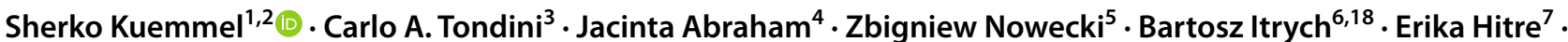 Bogusława Karaszewska $^{8}$. Alejandro Juárez-Ramiro ${ }^{9}$. Flavia Morales-Vásquez ${ }^{10}$. Jose Manuel Pérez-García ${ }^{11,19}$. Servando Cardona-Huerta ${ }^{12} \cdot$ Estefania Monturus $^{13} \cdot$ Marco Sequi $^{14,15}$. Eleonora Restuccia ${ }^{13} \cdot$ Mark Benyunes $^{16}$. Miguel Martín ${ }^{17}$}

1 Breast Unit, Kliniken Essen-Mitte, Henricistrasse 92, 45136 Essen, Germany

2 Clinic for Gynecology With Breast Center, CharitéUniversitätsmedizin Berlin, Berlin, Germany

3 Department of Onco-Hematology, ASST Papa Giovanni XXIII, Bergamo, Italy

4 Department of Clinical Oncology, Velindre Cancer Centre, Cardiff, UK

5 Klinika Nowotworów Piersi i Chirurgii Rekonstrukcyjnej, Centrum Onkologii-Instytut, Warsaw, Poland

6 Department of Oncology, Magodent, Warsaw, Poland

7 Department of Medical Oncology and Clinical Pharmacology "B", National Institute of Oncology, Budapest, Hungary

8 Przychodnia Lekarska KOMED, Konin, Poland

9 Medical Oncology, CME Consultorio de Medicina Especializada, Mexico City, Mexico

10 FUCAM, Instituto Nacional de Cancerología de Mexico, Mexico City, Mexico
11 Medical Oncology Department, Vall D’Hebron Institute of Oncology (VHIO), Hospital Universitari Vall D'Hebron, Barcelona, Spain

12 Centro de Cáncer de Mama, Hospital Zambrano-Hellion, Tecnológico de Monterrey, Monterrey, Mexico

13 Product Development Oncology, F. Hoffmann-La Roche Ltd, Basel, Switzerland

14 Biostatistics, F. Hoffmann-La Roche Ltd, Basel, Switzerland

15 Present Address: Biostatistics, PAREXEL, Milan, Italy

16 Product Development Oncology, Genentech, Inc., South San Francisco, CA, USA

17 Departamento de Medicina, Universidad Complutense de Madrid, Instituto de Investigación Sanitaria Gregorio Marañón, CIBERONC, Madrid, Spain

18 Present Address: Klinika Onkologii i Chorób Piersi CMKP, Centralny Szpital Kliniczny MSWiA, Warsaw, Poland

19 Present Address: International Breast Cancer Center (IBCC), Quiron Group, Barcelona, Spain 